\title{
Studi Komunikasi Budaya : Makna Shio pada Etnis Tionghoa dalam Memilih Pasangan Hidup
}

\author{
Chintia Oktavia, Suzy Azeharie \\ chintiaoktaviaa16@gmail.com,suzya@fikom.untar.ac,id
}

Fakultas Ilmu Komunikasi Universitas Tarumanagara

\begin{abstract}
The title of this research is Cultural Communication Study : Meaning Of Shio In A Chinese Ethic In Choosing Spouse. Shio is a symbol of Chinese animals that can be used as a benchmark for knowing personality, health, career, one's relationships and romance. This research is important to know the communication process of choosing a spouse through shio. The theory used is about communication, culture, cultural communication and shio. This study uses a qualitative approach through phenomenology methods. The study will use in-depth interviews with five Chinese informants. The research data obtained comes from in-depth interviews, non-past observation and literature studies. The conclusion of this study is that for Chinese ethnic shio is needed in choosing a spouse because it is believed that the communication process in the household is suitable and prevents differences in character.
\end{abstract}

Keywords: Communication, Culture, Cultural Communication, Chinese Ethnicity, Shio, Life Spouse

\begin{abstract}
Abstrak
Penelitian ini mengangkat tentang komunikasi budaya, makna shio pada etnis Tionghoa dalam memilih pasangan hidup. Shio merupakan dua belas simbol binatang Tionghoa yang dapat digunakan sebagai tolak ukur untuk mengetahui kepribadian, kesehatan, karier, pergaulan seseorang dan asmara. Penelitian ini penting untuk mengetahui proses komunikasi memilih pasangan hidup melalui shio. Teori yang digunakan adalah mengenai komunikasi, budaya, komunikasi budaya dan shio. Penelitian ini menggunakan pendekatan kualitatif melalui metode fenomenologi. Penelitian akan menggunakan wawancara mendalam terhadap lima informan etnis Tionghoa. Data penelitian yang diperoleh bersumber dari wawancara mendalam, observasi non-pastisipan dan studi pustaka. Penelitian ini menemukan bahwa bagi etnis Tionghoa, shio diperlukan dalam memilih pasangan hidup karena dipercaya agar proses komunikasi dalam rumah tangga cocok dan mencegah adanya perbedaan karakter.
\end{abstract}

Kata Kunci: Komunikasi, Budaya, Komunikasi Budaya, Etnis Tionghoa, Shio, Pasangan Hidup

\section{Pendahuluan}

Budaya merupakan fenomena dalam masyarakat untuk perlu dipertahankan dan diwariskan. Hal itu dikatakan oleh Weruin dalam buku yang berjudul Manusia, Kebudayaan dan Masyarakat bahwa kebudayaan diciptakan, dipelihara, dipelajari, dipertahankan dan diwariskan secara bersama-sama dalam masyarakat (Weruin, 2016:83).

Budaya ada sejak manusia dilahirkan dan diwariskan secara turun-temurun. Hal ini diperkuat oleh pernyataan Stewart L Tubbs dan Sylvia Moss dalam buku yang berjudul Human Communication yang mengemukakan bahwa budaya merupakan 
suatu cara hidup yang berkembang dan dimiliki bersama oleh sebuah kelompok orang yang diwariskan dari generasi ke generasi (Tubbs dan Moss, 2005:237). Mempelajari budaya termasuk dalam aspek komunikasi budaya.

Indonesia merupakan suatu bangsa yang terdiri atas berbagai etnis, ras dan budaya. Salah satu etnis di Indonesia yaitu etnis Tionghoa. Menurut Rani Usman, etnis Tionghoa sangat terikat dengan kebudayaan masa lampau serta taat pada ajaran konfusian yaitu kepercayaan yang kuat mengenai hubungan antara masa lampau dan masa kini. Mereka juga sangat menjunjung tinggi masa lampau serta cinta kebudayaan masa lampau. Masa lampau dipandang sebagai cermin keberhasilan masa kini (Usman, 2009:3).

Awal datangnya etnis Tionghoa ke nusantara karena terjadi interaksi antara orang Indonesia dengan orang Tionghoa. Hal ini diungkapkan oleh Rani Usman dalam buku yang berjudul Etnis Cina Perantauan di Aceh yang menulis bahwa kontak budaya antara etnis Tionghoa dengan masyarakat nusantara sudah berlangsung ratusan tahun (Usman, 2009:2).

Salah satu budaya masyarakat etnis Tionghoa adalah kepercayaan terhadap shio. Hal ini diungkapkan oleh Gabrielle Oliviani dalam jurnal yang berjudul Perancangan Board Game Mengenai Kedua Belas Shio dan Karakternya yang mengungkapkan bahwa shio merupakan kepercayaan masyarakat etnis Tionghoa yang telah dipercaya secara turun temurun hingga sekarang (Oliviani, 2015:1).

Tjong Liang Chen dalam buku Tjahyadi Budi Santosa yang berjudul Shio dan Feng Shui, mengatakan shio berasal dari bahasa Mandarin yang berarti "mirip", "persis" atau "seperti". Shio adalah simbol binatang Tiongkok yang terdiri dari dua belas shio yang dapat digunakan sebagai tolok ukur untuk mengetahui kepribadian, kesehatan, karier, asmara dan pergaulan seseorang (Santosa, 2018:14). Memilih pasangan hidup berdasarkan shio merupakan salah satu kebudayaan masa lalu yang masih berkembang sampai saat ini. Masyarakat Tionghoa mempercayai ada dua belas shio binatang dan percaya bahwa setiap shio binatang mewakili asmara setiap orang.

Dalam memilih pasangan hidup, etnis Tionghoa sangat memperhatikan ketika anaknya memilih pasangan hidup. Hal ini dikuatkan oleh Symphony Akelba Christian dalam jurnal yang berjudul Identitas Budaya Orang Tionghoa Indonesia yang mengungkapkan bahwa etnis Tionghoa sangat memperhatikan ketika anaknya memilih pasangan hidup (Christian, 2017:5).

Berdasarkan latar belakang di atas maka penulis tertarik untuk meneliti Studi Budaya Etnis Tionghoa Memilih Pasangan Hidup Berdasarkan Shio. Shio merupakan dua belas simbol binatang yang dapat digunakan sebagai tolak ukur salah satunya dalam memilih pasangan hidup. Sampai saat ini, etnis Tionghoa masih melakukan dan mewariskan budaya tersebut. Penulis ingin mengetahui bagaimana etnis Tionghoa memiliki pasangan hidup berdasarkan shio. Selain itu, alasan lainnya adalah karena belum ditemukan penelitian tentang memilih pasangan hidup berdasarkan shio oleh etnis Tionghoa.

\section{Metode Penelitian}

Dalam penelitian ini penulis menggunakan metode penelitian kualitatif dengan pendekatan fenomenologi. Menurut Sutanta, fenomenologi digunakan untuk memperoleh interpretasi terhadap pemahaman manusia atas fenomena yang tampak dan makna dibalik yang tampak yang muncul dalam kesadaran manusia untuk dapat mengetahui aspek subjektif tindakan seseorang dalam kehidupan sehari-hari perlu 
masuk ke dunia kesadaran atau konseptual subjek yang diteliti (Sutanta, 2019:27). Sementara menurut Edmund Husserls, fenomenologi merupakan suatu anggapan umum yang menunjuk pada pengalaman subjektif dari berbagai jenis dan tipe subjek yang telah diteliti (Moelong, 2009:14). Pendekatan fenomenologi, merupakan filsafat yang menempatkan kembali esensi-esensi dalam eksistensi bahwa manusia dan dunia tidak dapat dimengerti kecuali dengan bertitik tolak pada aktivitasnya (Harbiansyah, 2008:166).

Subjek penelitian penulis adalah etnis Tionghoa yang belum menikah, etnis Tionghoa sudah menikah, dan pasangan etnis Tionghoa sedangkan objek penelitian adalah proses komunikasi pada etnis Tionghoa. Data yang diperlukan penulis diperoleh berdasarkan metode pengumpulan data melalui wawancara mendalam, observasi non partisipan dan studi pustaka. Lima narasumber yang diwawancarai oleh penulis yakni: a) Suhu Manggala selaku pemilik Vihara Avalokitesvara Jelambar, b) Ie Li selaku ahli shio, c) Angeline Tjoe selaku etnis Tionghoa, d) Pasangan Aina dan Athiam selaku etnis Tionghoa, e) Linda selaku etnis Tionghoa.

Keabsahan data dari penelitian ini menggunakan teknik pemeriksaan keabsahan data dengan teknik triangulasi. Menurut Suwartono, triangulasi merupakan cara paling popular yang ditempuh untuk mengawal kesahihan data penelitian dengan istilah cross-check. Triangulasi merupakan pengumpulan dan pengecekkan data menggunakan perspekif berlainan. Triangulasi dilakukan dengan mengumpulkan data oleh lebih dari seorang peneliti (Suwartono, 2014:76).

\section{Hasil Temuan dan Diskusi}

Berdasarkan hasil wawancara penulis dengan Suhu Manggala terungkap bahwa etnis Tionghoa masuk ke Indonesia sejak ribuan tahun yang lalu. Suhu Manggala mengatakan bahwa pada saat Indonesia dijajah oleh Belanda, etnis Tionghoa datang dan menetap di Indonesia yang didatangkan oleh penjajah Belanda. Etnis Tionghoa awalnya didatangkan untuk menjadi buruh. Selain menjadi buruh, etnis Tionghoa juga menjadi tukang cukur rambut bahkan penarik becak di Indonesia (wawancara dengan Suhu Manggala di Vihara Avalokitesvara Jelambar pada tanggal 18 Juni 2019 Pukul 09.05 WIB).

Ie Li menambahkan bahwa etnis Tionghoa masuk ke Indonesia mengambil peranan yang sangat penting yaitu berjuang dalam melawan penjajahan Belanda dengan perjuangan mendapatkan kemerdekaan. Namun Ie Lie mengatakan bahwa etnis Tionghoa kerap dijadikan kambing hitam juga dipersalahkan dalam berbagai kerusuhan (wawancara dengan Ie Li di Taman Semanan Indah pada tanggal 17 Juni 2019 Pukul 17.00 WIB).

Berdasarkan hasil wawancara penulis dengan Suhu Manggala terungkap bahwa asal-usul shio seperti cerita dongeng. Dulu manusia bertengkar saling membalas dengan perkataan binatang contohnya "anjing lu", "sapi lu", dan "tikus lu" sehingga binatang tersebut merasa tidak nyaman, karena setiap manusia bertengkar selalu membawa nama binatang tersebut, akhirnya dibuatlah 12 shio. Sang Dewa meminta kepada 12 binatang tersebut untuk datang pada suatu malam, jika sampai duluan akan dijadikan shio yang pertama. Maka terbentuklah shio pertama tikus sampai yang terakhir shio babi (wawancara dengan Suhu Manggala di Vihara Avalokitesvara Jelambar pada tanggal 18 Juni 2019 Pukul 09.05 WIB).

Ie Li menambahkan bahwa shio merupakan lambang yang berbentuk binatang versi Mandarin. Ie Li juga mengatakan bahwa tahun kelahiran manusia berdasarkan 
shio yang berlaku pada tahun tersebut yang bertujuan lebih mengarah kepada bagaimana karakter seseorang berdasarkan shio (wawancara dengan Ie Li di Taman Semanan Indah pada tanggal 17 Juni 2019 Pukul 17.00 WIB).

Berdasarkan hasil wawancara penulis dengan Suhu Manggala, ia mengatakan bahwa shio sangat penting dalam menentukan pasangan hidup. Shio sangat penting dalam suatu hubungan pernikahan agar tidak terjadi ciong dalam rumah tangga. Ciong atau yang biasa dikenal dengan bertentangan. Pasangan yang menikah dengan shio yang tidak cocok akan mengakibatkan ciong kecil bahkan ciong besar. Ciong kecil misalnya sakit-sakitan dan ciong besar dapat menimbulkan kematian.

Suhu Manggala juga menjelaskan kelompok shio yang ciong atau tidak cocok dalam suatu pernikahan. Kelompok pertama yang tidak cocok yaitu tikus, kelinci, kuda dan ayam tidak dapat menjadi satu keluarga karena akan menimbulkan ciong. Kelompok yang kedua yaitu kerbau, naga, kambing, dan anjing tidak dapat menjadi satu keluarga. Kelompok ketiga yaitu macan, ular, kera dan babi tidak dapat menjadi satu keluarga. Jika dilanggar, pasangan tersebut tidak akan mempunyai anak, bahkan jika punya anak diantaranya harus ada yang mau jalan duluan artinya hidup tidak kekal atau meninggal ataupun salah satunya akan selingkuh. (wawancara dengan Suhu Manggala di Vihara Avalokitesvara Jelambar pada tanggal 18 Juni 2019 Pukul 09.05 WIB).

Pasangan suami istri yang bernama Athiam dan Aina Koo. Athiam lahir di Medan pada tanggal 21 Oktober 1975 berumur 44 tahun dan Aina juga lahir di Medan pada tanggal 10 Juni 1971 berumur 48 tahun. Athiam dan Aina merupakan pasangan suami istri yang menikah berdasarkan shio. Athiam shio kelinci dan Aina shio babi, mereka merasa cocok dalam pernikahan karena kecocokan shio. Penulis memilih Athiam dan Aina Koo sebagai informan karena mereka merupakan pasangan yang menikah dengan kecocokkan shio dan pernikahan mereka berjalan harmonis.

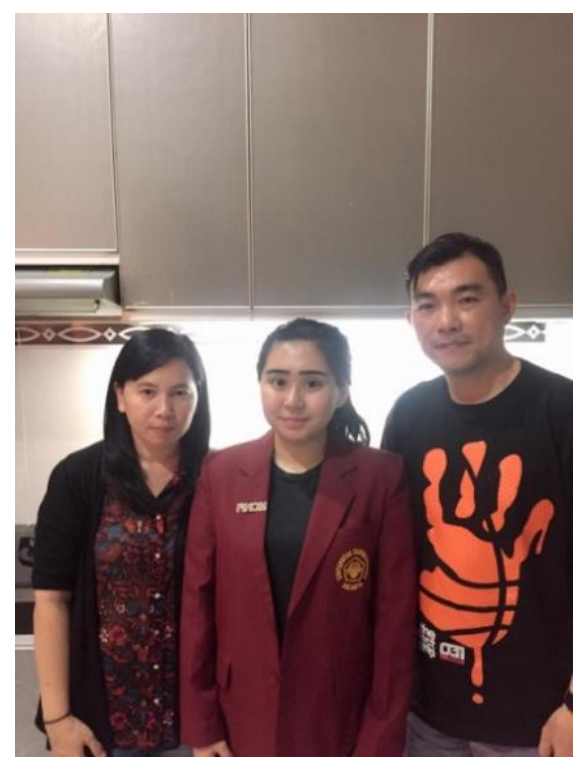

Gambar 1. Pasangan Athiam dan Aina Koo

(Sumber: dokumentasi penulis) 
Sementara berdasarkan hasil wawancara penulis dengan Ie Li yang merupakan ahli shio mengatakan Ie Li sangat percaya dengan shio dalam suatu hubungan. Ie Li menganggap melihat shio saat ingin melakukan suatu hubungan berpacaran atau menikah sangat penting, karena akan menentukan keharmonisan rumah tangga. Ie Li mengatakan setelah ia menikah dengan pasangan berdasarkan shio, Ie Li merasa sangat cocok dengan pasangan dan rumah tangga terasa harmonis.

Angeline mengatakan bahwa orang tuanya sangat percaya terhadap shio, sehingga Angeline dinasehati orang tuanya untuk mendapatkan pasangan yang memiliki kecocokan shio dengan Angeline. Angeline bercerita kalau dirinya kerap didekati oleh banyak laki-laki, tetapi Angeline tidak mau membantah nasehat orang tuanya. Angeline mempercayai shio dalam memilih pasangan hidup, ia melihat pernikahan orang tuanya harmonis karena menikah berdasarkan shio yang cocok, maka dia mengikuti nasihat orang tua untuk memilih pasangan hidup dengan melihat dari shio pasangan. Dia berusaha menolak bila ada laki-laki yang mendekatinya dengan shio yang tidak cocok.

Linda sangat mempercayai shio dalam memilih pasangan hidup dan membawa peruntungan. Linda menceritakan sedikit pengalaman akan shio yang membawa peruntungan yaitu sebelum mempunyai anak, perekonomian Linda sangat sulit, ketika memiliki anak dengan shio Tikus, Linda mampu membeli mobil dan usaha yang dijalankan selalu lancar karena kecocokkan antara shio monyet dengan shio tikus. Lalu lahir anak kedua dengan shio naga. Linda mengatakan shio monyet dan shio naga juga sangat cocok. Setelah lahir anak kedua, Linda mendapat usaha baru lagi yang dijalankan dari nol sampai tujuh tahun, hingga sang suami meninggal. Linda mengatakan bahwa ia sangat mempercayai shio karena benar-benar membawa rejeki dan melihat shio sangat mendukung. Linda juga mengatakan shio sangat berpengaruh dengan kecocokkan pasangan. Menurut Linda shio monyet sangat tidak cocok dengan shio macan dan shio harimau, baik dalam kecocokkan hubungan maupun dalam kelancaran usaha karena sangat bertentangan. Pengaruh shio yang cocok dalam rumah tangga menurut Linda adalah rumah tangga harmonis dan rejeki yang dijalankan pasti lancar.

\section{Simpulan}

Kesimpulan penelitian ini: 1) makna shio bagi etnis Tionghoa dipercaya agar kehidupan rumah tangga menjadi harmonis dan mencegah adanya perbedaan karakter; 2) Shio bagi etnis Tionghoa merupakan sesuatu yang sangat penting dalam memilih pasangan hidup; 3) Jika dalam rumah tangga terdapat perbedaan shio yang tidak cocok, etnis Tionghoa percaya bahwa akan terjadi perpisahan, perselingkuhan bahkan salah satunya akan meninggal; 4) Dalam budaya etnis Tionghoa memilih pasangan hidup berdasarkan shio, komunikasi dilakukan melalui menyebarluaskan dan menyampaikan informasi kepada penerima yang dituju; 5) Budaya dan komunikasi saling mempengaruhi, budaya etnis Tionghoa melihat karakter seseorang melalui shio dapat mempengaruhi komunikasi, sehingga komunikasi yang baik terjadi antar shio yang berbeda. 


\section{Ucapan Terima Kasih}

Penulis mengucapkan rasa terima kasih yang sebesar-besarnya kepada seluruh pihak yang telah membantu dan mendukung penulis selama proses penelitian ini berlangsung sampai dengan terbitnya publikasi atas hasil penelitian ini.

\section{Daftar Pustaka}

Christian, Akelba, Symphony (2017). Identitas Budaya Orang Tionghoa Indonesia. Vol 1 No 1. Hlm 1

Harbiansyah. (2008). Pendekatan Fenomenologi. Jurnal Komunikasi Vol 9 No 1. Hlm 166

Moleong, Lexy J (2013). Metodologi Penelitian Kualitatif. Bandung: Remaja Rosdakarya.

Moss, Sylvia \& Stewart, L, Tubbs. (2005). Human Communication. Bandung: Remaja Rosdakarya.

Olliviani, Gabrielle. (2015). Perancangan Board Game Mengenai Kedua Belas Shio dan Karakternya. Jurnal Desain Komunikasi, 1.

Santosa, Budi, Tjahyadi. (2018). Shio dan Feng Shui. Bandung: Laksana.

Sutanto, Mellisa Bilbert \& Ong Mia Farao Karsono. (2013). Pandangan Etnis Tionghoa Surabaya Terhadap Perempuan Etnis Tionghoa Shio Macan

Suwartono (2014). Metodologi Penelitian. Yogyakarta: Andi.

Usman, Rani. (2009). Etnis Cina Perantauan di Aceh. Jakarta: Yayasan Obor Indonesia.

Weruin, Urbanus Ura. (2016). Manusia, Kebudayaan dan Masyarakat. Tangerang: Pustaka Mandiri. 